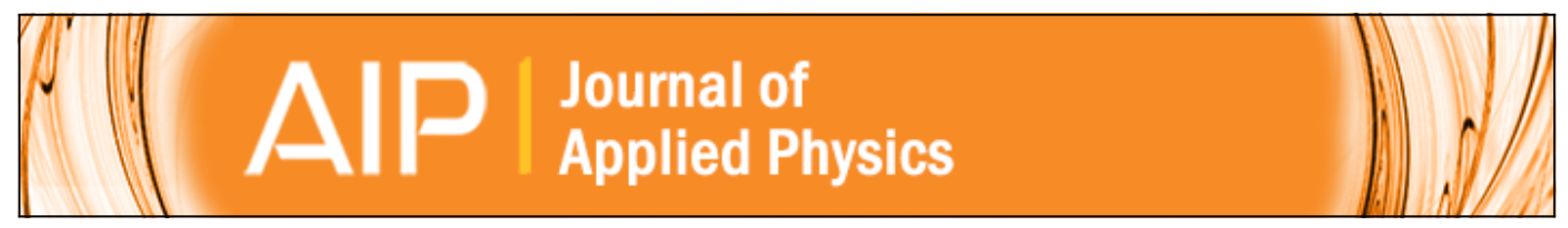

\title{
Dynamic annealing in ion implanted SiC: Flux versus temperature dependence
}

A. Yu. Kuznetsov, J. Wong-Leung, A. Hallén, C. Jagadish, and B. G. Svensson

Citation: Journal of Applied Physics 94, 7112 (2003); doi: 10.1063/1.1622797

View online: http://dx.doi.org/10.1063/1.1622797

View Table of Contents: http://scitation.aip.org/content/aip/journal/jap/94/11?ver=pdfcov

Published by the AIP Publishing

\section{Articles you may be interested in}

Amorphization and dynamic annealing of hexagonal $\mathrm{SiC}$ upon heavy-ion irradiation: Effects on swelling and mechanical properties

J. Appl. Phys. 105, 073513 (2009); 10.1063/1.3103771

A view of the implanted $\mathrm{SiC}$ damage by Rutherford backscattering spectroscopy, spectroscopic ellipsometry, and transmission electron microscopy

J. Appl. Phys. 100, 093507 (2006); 10.1063/1.2360150

Effect of ion implantation parameters on $\mathrm{Al}$ dopant redistribution in $\mathrm{SiC}$ after annealing: Defect recovery and electrical properties of $p$-type layers

J. Appl. Phys. 94, 2992 (2003); 10.1063/1.1598631

Influence of dynamic annealing on the shape of channeling implantation profiles in $\mathrm{Si}$ and $\mathrm{SiC}$

J. Appl. Phys. 93, 1004 (2003); 10.1063/1.1533092

Nanocrystal formation in $\mathrm{SiC}$ by $\mathrm{Ge}$ ion implantation and subsequent thermal annealing J. Appl. Phys. 91, 1520 (2002); 10.1063/1.1430539

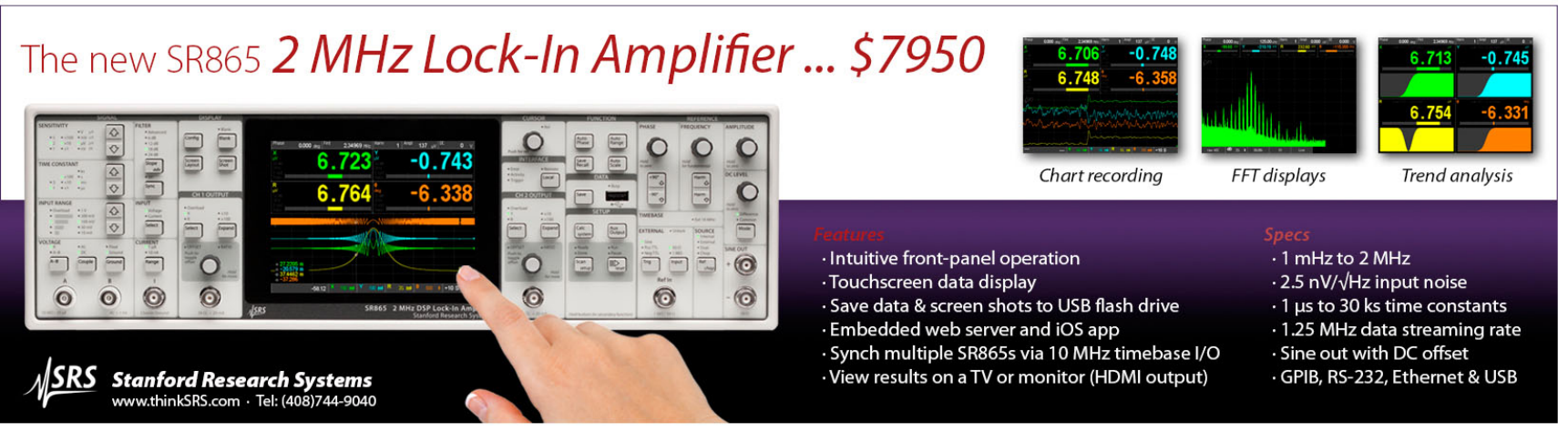




\title{
Dynamic annealing in ion implanted SiC: Flux versus temperature dependence
}

\author{
A. Yu. Kuznetsov ${ }^{\mathrm{a})}$ \\ Royal Institute of Technology, Solid State Electronics, Electrum 229, SE-164 40, Kista-Stockholm, Sweden \\ and Oslo University, Physical Electronics, Department of Physics, P.B. 1048 Blindern, \\ N-0316 Oslo, Norway \\ J. Wong-Leung \\ Australian National University, Department of Electronic Materials Engineering, Research School \\ of Physical Sciences and Engineering, Canberra, ACT 0200 Australia \\ A. Hallén \\ Royal Institute of Technology, Solid State Electronics, Electrum 229, SE-164 40, Kista-Stockholm, Sweden \\ C. Jagadish \\ Australian National University, Department of Electronic Materials Engineering, Research School \\ of Physical Sciences and Engineering, Canberra, ACT 0200 Australia
}

\section{B. G. Svensson}

Royal Institute of Technology, Solid State Electronics, Electrum 229, SE-164 40, Kista-Stockholm, Swedenand Oslo University, Physical Electronics, Department of Physics, P.B. 1048 Blindern, N-0316 Oslo, Norway

(Received 2 May 2003; accepted 8 September 2003)

\begin{abstract}
A strong influence of ion implantation flux on the accumulation of radiation damage, the so-called dose rate effect, is observed and systematically studied in $\mathrm{SiC} .100 \mathrm{keV} \mathrm{Si}^{+}$ions were implanted into bulk $4 \mathrm{H}-\mathrm{SiC}$ wafers using different ion fluxes $\left(1.9 \times 10^{10}-4.9 \times 10^{13}\right.$ ions $\left./ \mathrm{cm}^{2} \mathrm{~s}\right)$ and keeping the implantation dose constant at $5 \times 10^{14} \mathrm{Si}^{+} / \mathrm{cm}^{2}$. The implants were performed both at room and elevated temperatures, up to $220^{\circ} \mathrm{C}$. Rutherford backscattering spectrometry in the channelling mode using $2 \mathrm{MeV} \mathrm{He}^{+}$ions was employed to measure ion implantation damage profiles in the samples. For the flux interval used the most, pronounced dynamic annealing effect was detected at $80-160{ }^{\circ} \mathrm{C}$, having an activation energy of $1.3 \mathrm{eV}$. For example, at $100^{\circ} \mathrm{C}$ the amount of disordered $\mathrm{Si}$ atoms at the projected ion range is reduced by a factor of 4 by decreasing the ion flux from $4.9 \times 10^{13}$ to $1.9 \times 10^{10}$ ions $/ \mathrm{cm}^{2} \mathrm{~s}$. The results are discussed in terms of migration and annihilation of intrinsic type defects for both the $\mathrm{Si}$ - and $\mathrm{C}$-sublattices. In addition, two regions for the damage accumulation - at the surface and at the damage peak for $100 \mathrm{keV} \mathrm{Si}^{+}$ions - are observed.
\end{abstract}

(C) 2003 American Institute of Physics. [DOI: 10.1063/1.1622797]

\section{INTRODUCTION}

Ion implantation is a key technology to fabricate integrated electronic devices and, in particular, it is probably the only accessible tool to locally dope $\mathrm{SiC}$ since in-diffusion doping techniques require very high temperatures, $\geqslant 1800^{\circ} \mathrm{C}$, for most doping elements. However, the implantation process produces radiation defects, which have to be removed during dopant activation anneals. The understanding of radiation defect annealing mechanisms in $\mathrm{SiC}$ is not mature, partly because of the complexity of the initial radiation damage that is a strong function of the implantation parameters. Most of the efforts to understand the nature of radiation effects in $\mathrm{SiC}$ have been devoted, so far, to investigate the accumulation of radiation damage as a function of ion implantation energy, dose, and substrate temperature. ${ }^{1,2}$ There is, however, one parameter that has not been investigated in detail, namely, the ion flux or dose rate. It is known

a) Author to whom all correspondence should be addressed; electronic mail: kuznet@imit.kth.se and andrej.kuznetsov@fys.uio.no since the late 1960s that the accumulation of radiation damage in semiconductors may be very sensitive to how fast the implantation dose is collected. ${ }^{3}$ The phenomenon is often referred to as the dose rate effect (dynamic annealing) in the literature and has been reported to play an important role in several semiconductors, e.g., in $\mathrm{Si}, \mathrm{Ge},{ }^{4}$ and more recently in $\mathrm{GaAs},{ }^{5,6} \mathrm{InP}^{7}$ and GaN. ${ }^{8}$ Surprisingly, quite little has been reported on the dose rate effect in $\mathrm{SiC}$ in literature taking into account severe problems linked to manifestations of implantation defects in $\mathrm{SiC}$ applications. Very recently, new measurements of radiation damage evolution in ion implanted $\mathrm{SiC}$ have been reported by Ohno and Amemiya ${ }^{9}$ and Zhang et al. ${ }^{10}$ also as a as a function of flux/substrate temperatures. These observations are consistent with a point stated by Wendler et al. ${ }^{1}$ that the instantaneous defect concentration and the resulting damage might naturally depend on the flux conditions in ion implanted $\mathrm{SiC}$ too. Indeed, the dynamic defect concentration during irradiation depends on a balance between defect generation and annihilation rates. For example, if the ion flux is low enough, defects will annihilate at a faster rate than they are generated and the accumulated 
defect density may never reach the critical value for amorphization. The substrate temperature plays an obvious role here since the defect annihilation process is thermally activated. Generally speaking it is possible to find a dose-rate interval corresponding to a temperature interval where a transition between high and low damage accumulation takes place. There is, however, a practical consideration if very high rates are accessible and/or very low rates are feasible to reach a desired dose within a reasonable time. In the present work we report on a strong influence of the ion implantation flux on the accumulation of radiation damage in $4 \mathrm{H}-\mathrm{SiC}$ at temperatures between 80 and $160^{\circ} \mathrm{C}$, extract the activation energy for the dynamic annealing, and discuss the nature of this process.

\section{EXPERIMENT}

The samples used are Cree $4 \mathrm{H}$-SiC $n$-type bulk wafers with a resistivity of $0.015 \Omega \mathrm{cm}$ grown $8^{\circ}$-off the $\langle 0001\rangle$ direction. $100 \mathrm{keV} \mathrm{Si}^{+}$ions were implanted in a normal direction using different ion fluxes of $1.9 \times 10^{10}-4.9$ $\times 10^{13}$ ions $/ \mathrm{cm}^{2} \mathrm{~s}$ and keeping the implantation dose constant at $5 \times 10^{14} \mathrm{Si}^{+} / \mathrm{cm}^{2}$. The incident beam, scanned over an area of $\sim 30 \times 30 \mathrm{~mm}^{2}$, was transmitted through a $10 \times 10$ $\mathrm{mm}^{2}$ aperture to ensure the implantation uniformity. The ion flux was varied by changing the intensity of the unscanned beam. The precision of the flux control was around a few percent (except for the lowest flux where the uncertainty was $\pm 50 \%$ ). The implants were performed both at room and elevated temperatures, up to $220^{\circ} \mathrm{C}$. The substrate temperature was controlled within an accuracy of $\pm 5^{\circ} \mathrm{C}$. After implantation the samples were analyzed by Rutherford backscattering spectrometry in the channelling mode (RBS/C) along the $\langle 0001\rangle$ direction using $2.0 \mathrm{MeV} \mathrm{He}^{+}$ions, backscattered into detectors at $100^{\circ}$ and $170^{\circ}$ with respect to the incident beam direction. Glancing $\left(100^{\circ}\right)$ and backscattering $\left(170^{\circ}\right)$ detectors are normally used to reach higher depth and mass resolution, respectively. A charge of $60 \mu \mathrm{C}$ was normally accumulated at the target for each RBS/C spectrum. Dechanneled fractions $\left[\chi_{R}(x)\right]$ have been evaluated in all samples in accordance with the formalism by Eisen ${ }^{11}$ and the relative damage $\left(N / N_{0}\right)$ has been calculated using a standard iteration procedure $N / N_{0}=\left[\chi(x)-\chi_{R}(x) / 1-\chi_{R}(x)\right]$, where $\chi(x)$ is a normalized backscattering yield in a channeling direction. ${ }^{11}$

\section{RESULTS AND DISCUSSION}

Figure 1 shows examples of the relative damage versus channel number of samples implanted using different ion fluxes at $100^{\circ} \mathrm{C}$ (a) and $160{ }^{\circ} \mathrm{C}$ (b). Insets in Fig. 1 show also raw RBS/C spectra as collected by the glancing detector. All spectra in the insets have two typical signatures that are related to carbon and silicon damage profiles starting at channels 150 and 275, respectively. For clarity, only the silicon part of the spectra (recalculated into relative damage) is presented in the main part of Fig. 1. It is clearly seen from Fig. 1 that the relative damage gradually increases with increasing ion flux for both the 100 and $160^{\circ} \mathrm{C}$ implants and the effect is very pronounced. Specifically for the $100{ }^{\circ} \mathrm{C}$ implants, the amount of displaced $\mathrm{Si}$ atoms in the lowest flux

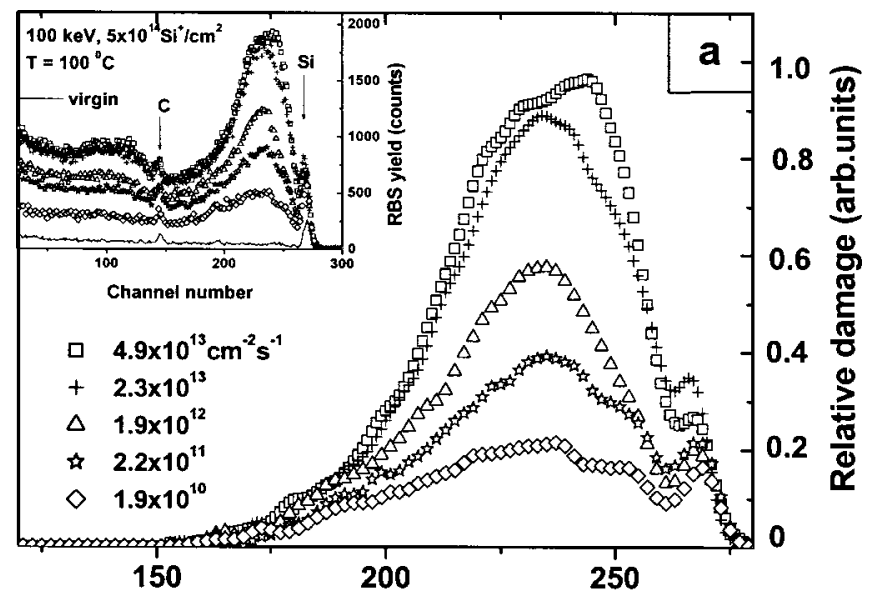

\section{Channel number}

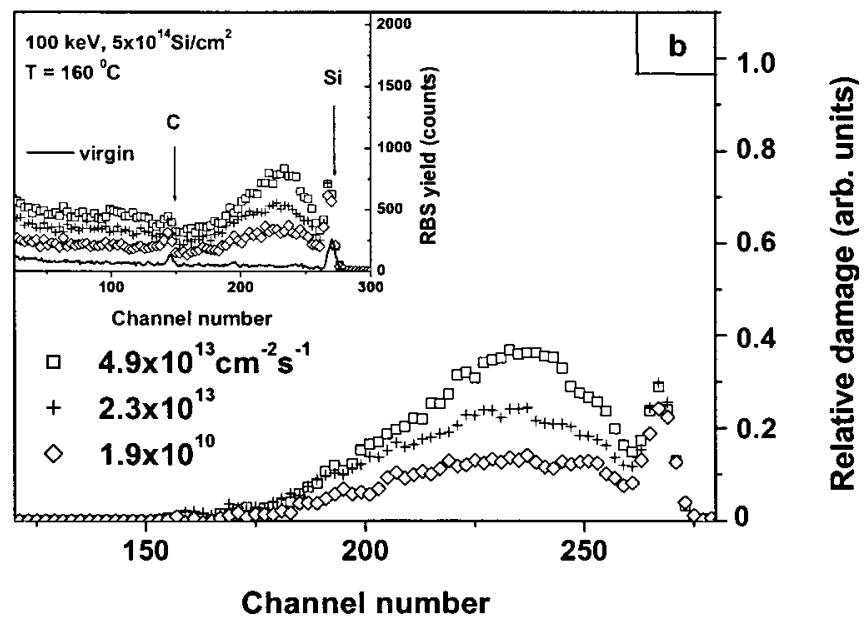

FIG. 1. Relative damage in silicon sublattice vs channel profiles of samples implanted using different ion fluxes (find symbols in the diagrams) at $100^{\circ} \mathrm{C}$ (a) and $160{ }^{\circ} \mathrm{C}$ (b). The inserts represent raw RBS/C spectra of the samples. Solid lines represent virgin spectra. Random normalized yield reaches $\sim 2000$ count/s in the silicon part of the insets (spectrum not shown).

sample is reduced by a factor of 4 relative to that for the highest flux sample where the RBS/C yield almost reached the random level (in the range of $\sim 2000$ counts in the insets of Fig. 1), i.e., the sample is close to amorphization. The integral disorder in samples implanted at $160^{\circ} \mathrm{C}$ is, however, lower when compared to that in the samples implanted at $100{ }^{\circ} \mathrm{C}$ for the corresponding fluxes. The comparison between Figs. 1(a) and 1(b) shows that the difference in the accumulation of the implantation damage using low- and high-flux conditions is much less pronounced for the implants performed at $160^{\circ} \mathrm{C}$. It suggests that even the highest flux used at $160^{\circ} \mathrm{C}$, specifically $4.9 \times 10^{13} \mathrm{Si}^{+} / \mathrm{cm}^{2} \mathrm{~s}$ where the implantation takes just about $10 \mathrm{~s}$, is too low to efficiently compete with the rate of defect annihilation. Similar trends for the accumulation of the radiation damage as a function of temperature and dose-rate have been measured at 120 and $140^{\circ} \mathrm{C}$. In contrast, measurements performed on the samples implanted at $80^{\circ} \mathrm{C}$ reveal that the "high-damageconditions" are reached already at the flux of 2.3 $\times 10^{13} \mathrm{Si}^{+} / \mathrm{cm}^{2} \mathrm{~s}$ and the damage produced by the lowest flux $\left(1.9 \times 10^{10} \mathrm{Si}^{+} / \mathrm{cm}^{2} \mathrm{~s}\right)$ is significantly higher than that at 


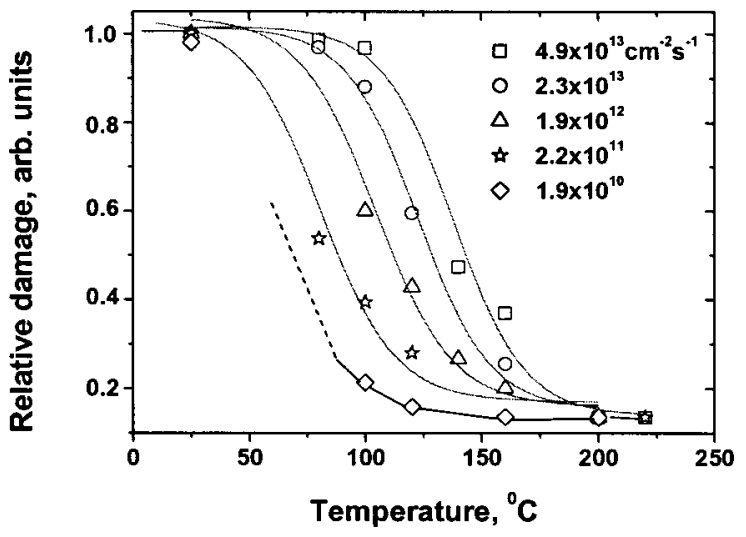

FIG. 2. The relative damage as measured in the samples implanted with different dose rates (find symbols in the diagram) keeping the substrate temperature in the range $25-220{ }^{\circ} \mathrm{C}$.

$100{ }^{\circ} \mathrm{C}$. These results are consistent with the data reported in Refs. 9 and 10 and confirm that the dynamic annealing during ion implantation into $\mathrm{SiC}$ is thermally activated and takes place in a way similar to that for other semiconductors. ${ }^{3-8}$ It is important to emphasize that the observed phenomenon is due to "dynamic" defect annihilation during ion implantation. A control experiment, where a sample implanted at $120^{\circ} \mathrm{C}$ using the flux of $2.3 \times 10^{13} \mathrm{Si}^{+} / \mathrm{cm}^{2} \mathrm{~s}$ (i.e., exposed to the ion beam for about $23 \mathrm{~s}$ ) was post annealed for $10 \mathrm{~h}$ at $120^{\circ} \mathrm{C}$, did not reveal any measurable difference between the damaged profiles before and after annealing. The duration of the post-anneal was chosen to be comparable with the exposure time used for the lowest flux implant.

The crystalline disorder after all implants has been represented by the relative height of each damage profile at the depth corresponding to the projected range of $100 \mathrm{keV} \mathrm{Si}^{+}$ ions (main damage peak). The damage yields $Y_{a}$ are shown in Fig. 2 versus substrate temperature and it can be seen that a similar characteristic shape of a crystalline-to-amorphous transition is observed for all the dose rates. In accordance with the formalism from Ref. 12, the transition is fitted by a simple inverse exponential function $Y_{a}=a+b[1+\exp \{\delta(T$ $\left.\left.\left.-T_{c}\right)\right\}\right]^{-1}$, where the constant $\delta$ describes the width of the phase transition, see solid curves in Fig. 2. The same fitting parameters except for the value of the so-called critical transition temperature $T_{c}$ representing the inflection point of the damage-versus-temperature curve for a give dose rate have been used to fit the equation above to the $Y_{a}$ values as measured for $4.9 \times 10^{13}, \quad 2.3 \times 10^{13}, \quad 1.9 \times 10^{12}$, and 2.2 $\times 10^{11}$ ions $/ \mathrm{cm}^{2} / \mathrm{s}$ implantation fluxes. The fitting procedure has also been performed for the lowest dose rate implants, $1.9 \times 10^{10}$ ions $/ \mathrm{cm}^{2} \mathrm{~s}$ and diamonds in Fig. 2, but the uncertainty in the determination of the $T_{c}$ becomes quite high due to the lack of experimental points between 25 and $100{ }^{\circ} \mathrm{C}$. Figure 3 summarizes the results obtained for the critical transition temperatures at four different dose rates (plus the "uncertain" point at the lowest rate). The data are found to follow an Arrhenius dependence with an activation energy $E_{a}$ of $1.3 \pm 0.1 \mathrm{eV}$, which represents the temperature dependence of the physical process(es) limiting the rate of dynamic annealing (defect annihilation) during high dose implantation into $4 \mathrm{H}-\mathrm{SiC}$.

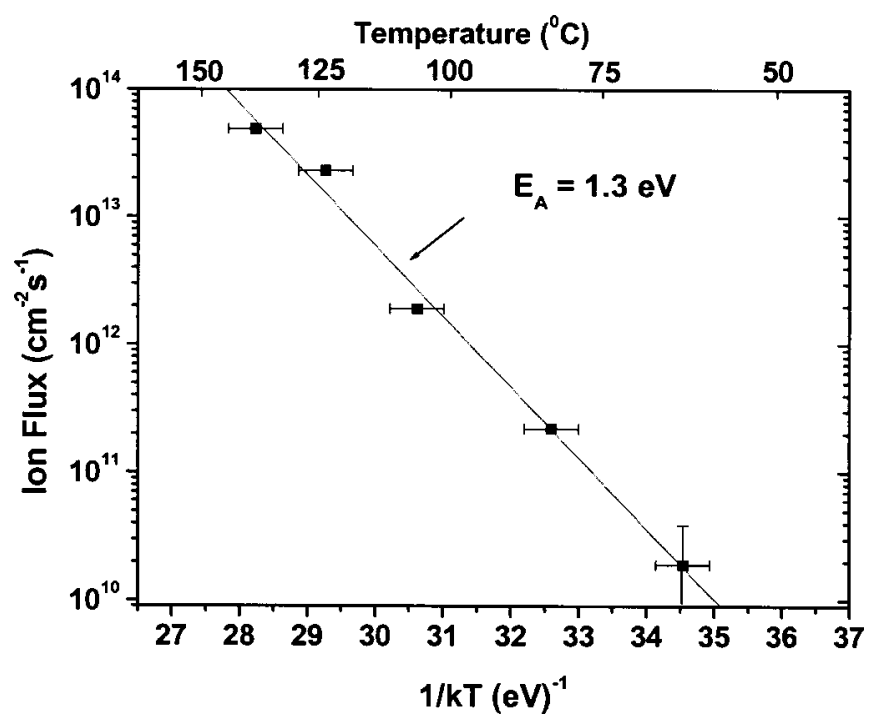

FIG. 3. Arrhenius plot for the ion flux vs the critical transition temperature $T_{c}$ as extracted from the fitting to the experimental data in Fig. 2.

In principle, several different defects and their various annealing routes may be considered to be responsible for the dose rate effect in $\mathrm{SiC}$ in the studied temperature range, 25$200^{\circ} \mathrm{C}$. However, combining literature data and the present results the following scenario for a microscopic mechanism causing dynamic annealing during ion implantation may be proposed. During ion bombardment all possible kinds of elementary intrinsic defects, $\mathrm{Si}_{i}, \mathrm{C}_{i}, V_{\mathrm{C}}$, and $V_{\mathrm{Si}}$, where index $i$ denotes interstitials and $V$ denotes vacancies, and combinations thereof are formed. Recent results of electron paramagnetic resonance measurements show that $C_{i}$, in a split interstitial configuration, anneals out in the temperature range of $150-200^{\circ} \mathrm{C}$ (Refs. 13 and 14) and computational experiment within the framework of density functional theory using local density approximation performed by Bockstedte et al. ${ }^{15}$ yield a reaction barrier of $\sim 1.4 \mathrm{eV}$ for the annihilation of $\mathrm{C}_{i}$ in a neutral charge state $\left(\mathrm{C}_{i}+V_{\mathrm{C}} \rightarrow \varnothing\right)$. Further, the calculation also predicts an activation energy of $\sim 1.4 \mathrm{eV}$ for the migration of $\mathrm{Si}_{i}$ (split interstitial configuration) in $n$-type $\mathrm{SiC}$ and a substantially lower barrier for the annihilation process. Here, it should be emphasized that we observe a similar decrease in the number of displaced atoms on both the Si- and C-sublattices, consistent with the theoretical prediction that the annihilation should occur with a similar activation energy for both sublattices. Another experimental observation of defect motion at these temperatures is the formation of the dominant $Z_{1}$-defect detected by deep level transient spectroscopy at low irradiation doses. ${ }^{16}$ In particular, a transition from an unstable $E_{c}-0.62 \mathrm{eV}$ position to a $Z_{1}$-like signature at $E_{c}-0.7 \mathrm{eV}$ occurs $\left(E_{c}\right.$ denotes conduction band edge). The nature of the $Z_{1}$-center is not fully understood yet but since the transformation occurs in a similar temperature range as the dose rate effect takes place it is consistent to assume that both $\mathrm{Si}_{i}$ and $\mathrm{C}_{i}$ mediate the transition.

In addition, Fig. 1 shows also an interesting shape of the damage profiles where two regions for damage accumulation - at the surface and at the damage peak for $100 \mathrm{keV} \mathrm{Si}^{+}$ions 
- are found. Again, considering, for clarity reason, only the silicon part of the spectra (the main parts in Fig. 1), an interesting evolution of these profiles with respect to the flux conditions is observed. The relative size of the surface damage peak is much more significant for the low flux implants. In particular, see for example Fig. 1(b), the implantation induced disorder in the surface region of the sample implanted at $160{ }^{\circ} \mathrm{C}$ using the flux of $1.9 \times 10^{10} \mathrm{Si}^{+} / \mathrm{cm}^{2} \mathrm{~s}$ is almost three times higher than that at the depth corresponding to the ion range (where the dominant part of the nuclear energy losses for the incident $100 \mathrm{keV} \mathrm{Si}^{+}$ions takes place). As the ion flux increases the intensity of the surface peak remains unchanged or increases very slightly for both the 160 and $100{ }^{\circ} \mathrm{C}$ implants. As discussed earlier, this is in direct contrast to the intensity of the main damage peak. Assuming that the defects have a small migration length, one may suggest that the dynamic annealing in $\mathrm{SiC}$ is a rather localized process, where long-distance diffusion of point defects plays a minor role since in that case much smoother profiles are expected than obtained experimentally. This argument may be in favor of the heterogeneous mode of amorphization in $\mathrm{SiC}$ during the implantation conditions used. On the other hand, the evolution of the damage profiles in Fig. 1 does not fully exclude long-range defect redistribution if to assume that stable defect complexes with low mobility are preferentially formed at the disordered surface through reactions between migrating defects.

\section{CONCLUSIONS}

In summary, a strong influence of ion implantation flux on the accumulation of radiation damage, the so-called dose rate effect, is observed in $4 \mathrm{H} \mathrm{SiC}$ implanted with $100 \mathrm{keV} \mathrm{Si}^{+}$ions at $80-160^{\circ} \mathrm{C}$. The dynamic annealing is found to be thermally activated with an energy of $\sim 1.3 \mathrm{eV}$, and the transition from high to low damage accumulation in $\mathrm{SiC}$ can be engineered by combining ion flux and implantation temperature. In particular, at $100{ }^{\circ} \mathrm{C}$ the amount of disordered $\mathrm{Si}$ atoms is reduced by a factor of 4 by decreasing the ion flux from $4.9 \times 10^{13}$ to $1.9 \times 10^{10}$ ions $/ \mathrm{cm}^{2} \mathrm{~s}$. The results are discussed in terms of migration and annihilation of intrinsic type defects for both $\mathrm{Si}$ - and $\mathrm{C}$-sublattices. In addition, two regions for the damage accumulation-at the surface and at the damage peak for $100 \mathrm{keV} \mathrm{Si}^{+}$ions-are observed.

\section{ACKNOWLEDGMENTS}

Partial financial support for this work was received from the Swedish Foundation for Strategic Research (SSF), the Swedish Foundation for International Cooperation in Research and Higher Education (STINT), the Norwegian Research Council (NFR), and the Nordic Academy for Education and Research Training (NorFA). One of the authors (J.W.L.) acknowledges the Australian Research Council for funding under the fellowship program.

${ }^{1}$ E. Wendler, A. Heft, and W. Wesch, Nucl. Instrum. Methods Phys. Res. B 141, 105 (1998).

${ }^{2}$ See, e.g., W. Jiang, W. J. Weber, S. Thevuthsan, and D. E. McCready, Nucl. Instrum. Methods Phys. Res. B 143, 333 (1998), and references therein.

${ }^{3}$ F. L. Vook and H. J. Stein, Radiat. Eff. 2, 26 (1969).

${ }^{4}$ Most of the original reports have been summarized in Ion Implantation and Beam Processing, edited J. S. Williams and J. M. Poate (Academic, New York, 1984); F. Priolo and E. Rimini, Mater. Sci. Rep. 5, 320 (1990).

${ }^{5}$ T. E. Haynes and O. W. Holland, Appl. Phys. Lett. 59, 452 (1991).

${ }^{6}$ R. A. Brown and J. S. Williams, J. Appl. Phys. 83, 7533 (1998).

${ }^{7}$ U. G. Akano, I. V. Mitchel, and F. R. Shepherd, Appl. Phys. Lett. 62, 1670 (1993).

${ }^{8}$ S. O. Kucheyev, J. S. Williams, C. Jagadish, J. Zou, and G. Li, Phys. Rev. B 62, 7510 (2000).

${ }^{9}$ T. Ohno and K. Amemiya, Mater. Sci. Forum 389-393, 823 (2002).

${ }^{10}$ Y. Zhang, W.-J. Weber, W. Jiang, C.-M. Wang, A. Hallén, and G. Possnert, J. Appl. Phys. 93, 1954 (2003).

${ }^{11}$ T. Eisen, in Channeling, D. V. Morvan, ed. (Wiley, New York, 1973), p. 326.

${ }^{12}$ P. J. Schultz, C. Jagadish, M. C. Ridgway, R. E. Elliman, and J. S. Williams, Phys. Rev. B 44, 9118 (1991).

${ }^{13}$ H. Itoh, M. Yoshikawa, I. Nashiyama, S. Misawa, H. Okumura, and S. Yoshida, J. Electron. Mater. 21, 707 (1992).

${ }^{14}$ N. T. Son, P. E. Hai, and E. Jansen, Phys. Rev. B 63, 201201 (2001).

${ }^{15}$ M. Bockstedte, M. Heid, A. Mattausch, and O. Pankratov, Mater. Sci. Forum 389-393, 471 (2002).

${ }^{16}$ J. P. Doyle, M. K. Linnarsson, P. Pellegrino, N. Keskitalo, B. G. Svensson, A. Schöner, N. Nordell, and J. L. Lindström, J. Appl. Phys. 84, 1354 (1998). 